\title{
PREVALENCE, ASSOCIATED FACTORS, AND HELP SEEKING BEHAVIOR RELATED TO PSYCHOLOGICAL DISTRESS AMONG INTERNATIONAL STUDENTS AT UNIVERSITI KEBANGSAAN MALAYSIA
}

\author{
Khadiga Mohsen Kahwa ${ }^{1}$ and Aniza Ismail ${ }^{1}$ \\ ${ }^{1}$ Department of Community Health, Faculty of Medicine, Universiti Kebangsaan Malaysia Medical Centre, Kuala \\ Lumpur, Malaysia
}

Corresponding author: Aniza Ismail

Email: aniza@ppukm.ukm.edu.my

\begin{abstract}
Depression, anxiety, and stress are associated with decreased role functioning, productivity, and quality of life. International students are more prone to psychological distress as they face many stressors while studying abroad. The objectives of the study were to determine the prevalence and associated factors of depression, anxiety, and stress among international students, their help-seeking behavior and their awareness of the available on-campus mental support services. A cross-sectional study with a purposive sampling method was performed on 280 international students at Universiti Kebangsaan Malaysia (UKM) between the age of 18 and 35 years. The Depression Anxiety Stress Scale-21 (DASS-21) questionnaire was used anonymously to assess the mental health of students. Soci-demographic, help-seeking behavior, and awareness data were obtained. Independent sample t-test, one-way Analysis of Variance (ANOVA) test, and Multiple Linear Regression were used to explore associated factors. The overall prevalence of depression, anxiety, and stress among international students was 58.9\%, 71.8\%, and 53.9\% respectively. Age was significantly associated with depression and anxiety. Ethnicity showed a significant association with depression and stress. No other factors were found to be significantly associated with psychological distress. Only $9.6 \%$ of the international students had sought help from on-campus mental support services. Students who were aware of the presence of such services were only $21.4 \%$ of the participants. In conclusion, the recent study showed a high prevalence of psychological distress and low help-seeking behavior among international students in Malaysia. This provided data that could be used in intervention programs to improve the mental health of the increasing number of international students in Malaysia.
\end{abstract}

Keywords: Anxiety, depression, stress, help-seeking behavior, students

\section{INTRODUCTION}

Depression, anxiety, and stress are extremely prevalent among university students, and their prevalence appears to be increasing ${ }^{1-3}$. These psychological problems have a bad impact on the students' quality of lives which in turn can interfere with the healthy adaptation and coping of the international students with the new environment. Psychological distress (PD) is a state of psychological discomfort usually experienced as sadness, depression, stress, and anxiety ${ }^{4,5}$. It often co-exists with somatic complaints, chronic conditions and syndromes that have no medical explanation ${ }^{6}$. Risk factors for PD include stressrelated factors and sociodemographic factors ${ }^{4}$ such as Age, gender, race, marital status, socioeconomic level, and study program ${ }^{7}$.

International students are a high-risk group of people who need to be connected with care and support as it is very important to help them develop effective coping strategies for their mental health problems. Since international students come from different cultures and environments, care should be given to increase their awareness about mental illness and professional help-seeking behavior for psychological distress. It was demonstrated that more than two-thirds of young people did not seek help for their psychological problems ${ }^{8-10}$. Sometimes, students may not seek help from professionals since they are unaware of the presence of mental support services at their universities ${ }^{11}$. It has been historically reported that international students underutilized oncampus mental support services ${ }^{12,13}$.

Malaysia is a popular destination for international students worldwide. It was recognized by the United Nations Educational, Science and Cultural Organization (UNESCO) as one of the most ten preferred destinations for post-secondary education among international students ${ }^{14}$. From Public Health perspectives, it is very crucial to early detect and prevent mental health disorders among international university students. Although previous studies have been conducted in Malaysia to assess the prevalence and associated factors of depression, anxiety, and stress among Malaysian university students ${ }^{7.19}$, more studies are still needed to explore and highlight the prevalence, 
associated factors, and help-seeking behavior of psychological distress among international university students in Malaysia. This will help to develop and evaluate more effective preventive and therapeutic interventions to these conditions improve the quality of life of the international students and encourage them to seek medical help.

\section{METHODS}

A cross-sectional study was performed on 280 undergraduate and postgraduate international students at Universiti Kebangsaan Malaysia (UKM) between the ages of 18 and 35 years. Purposive sampling method was used to select the sample population of this study.

Participants were given hard copies of a selfadministered questionnaire which consisted of 4 sections: DASS-21 questionnaire, sociodemographic data, study program, and lastly help-seeking behavior and awareness of oncampus mental support services. The Depression Anxiety Stress Scale-21 (DASS-21) measures characteristics and severity of a range of symptoms of depression, anxiety, and stress ${ }^{15}$.
DASS 21-item, is a modified version of the original Scale of DASS-42, has many advantages as it is more convenient for people with poor concentration since it is shorter ${ }^{16}$. Reliability assessed using Cronbach's alpha scores rate the Depression scale at 0.91 , the Anxiety scale at 0.84 , and the Stress scale at 0.90 in the normative sample $^{7}$. The questionnaire consists of 21 items, a set of 3 self-report scales to measure the negative emotional states of depression, anxiety, and stress, seven items for each psychological state ${ }^{15}$. The students were asked to score the extent of various symptoms they experienced over the past week. Each item was scored on a 4-point Likert scale $(0=$ Did not apply to me at all, $1=$ Applied to me to some degree, or some of the time, $2=$ Applied to me to a considerable degree, or a good part of the time, and 3 = Applied to me very much, or most of the time $)^{7}$. According to the manual guidelines $^{15}$, scores from each subscale were summed up and multiplied by two to meet the original 42 items. Each subscale score ranged between $0-42$, and the severity scores are presented in Table 1. Higher scores indicated greater levels of psychological distress ${ }^{15}$.

Table 1 Lovibond scoring scale for psychological mood

\begin{tabular}{llll}
\hline & Stress scale & Anxiety scale & Depression scale \\
\hline Normal & $0-14$ & $0-7$ & $0-9$ \\
Mild & $15-18$ & $8-9$ & $10-13$ \\
Moderate & $19-25$ & $10-14$ & $14-20$ \\
Severe & $26-33$ & $15-19$ & $21-27$ \\
Very severe & $\geq 34$ & $\geq 20$ & $\geq 28$ \\
\hline
\end{tabular}

The sociodemographic data section consisted of 5 questions about sociodemographic information of the participants such as age, gender, ethnicity, marital status, and monthly income. The study program section contained 1 question about the study program and the educational level of the participants. At the same time, Help-seeking behavior and awareness of the on-campus mental support services section included two dichotomous questions regarding help-seeking behavior for psychological distress and awareness of the presence of on-campus mental support services.

Data analysis was performed using IBM Statistical Package for Social Sciences (SPSS) version 23. Data cleaning was done to remove any missing values. Age, gender, ethnicity, marital status, study program, socioeconomic level, help-seeking behavior, and awareness were presented in number and percentage. In comparison, the outcome variables such as depression, anxiety, and stress scores were presented as mean and standard deviation. The independent samples $t$ test and the one-way ANOVA test were used to test the differences in means of depression, anxiety, and stress scores with study variables. Multiple Linear Regression was performed to assess the association of depression, anxiety, and stress scores with all factors studied. We considered a p-value less than 0.05 to be statistically significant, with $95 \%$ of confidence interval.

\section{RESULTS}

\section{Characteristics of study participants}

Table 2 represents the characteristics of the study participants. The total number of students who participated was 280 students. 
Table 2 Characteristics of the study participants

\begin{tabular}{|c|c|c|}
\hline \multirow{2}{*}{ Variables } & \multicolumn{2}{|c|}{ Study participants $(n=280)$} \\
\hline & Number & Percent (\%) \\
\hline \multicolumn{3}{|l|}{ Age Group: } \\
\hline & 25 & 8.9 \\
\hline $21-24$ years & 60 & 21.4 \\
\hline $25-35$ years & 195 & 69.6 \\
\hline \multicolumn{3}{|l|}{ Gender: } \\
\hline Female & 66 & 236 \\
\hline Male & 214 & 76.4 \\
\hline \multicolumn{3}{|l|}{ Nationality: } \\
\hline Africans & 20 & 7.1 \\
\hline Arabs & 168 & 60.0 \\
\hline Asians & 83 & 29.6 \\
\hline Others & 9 & 3.2 \\
\hline \multicolumn{3}{|l|}{ Educational level: } \\
\hline Undergraduate & 43 & 15.4 \\
\hline Postgraduate & 237 & 84.6 \\
\hline \multicolumn{3}{|l|}{ Study Program: } \\
\hline Non-medical & 237 & 84.6 \\
\hline Medical/paramedical & 43 & 15.4 \\
\hline \multicolumn{3}{|l|}{ Monthly Income: } \\
\hline$<2000 \mathrm{RM}$ & 140 & 50.0 \\
\hline $2000-5000$ RM & 115 & 41.1 \\
\hline >5000 RM & 25 & 8.9 \\
\hline \multicolumn{3}{|l|}{ Marital Status: } \\
\hline Married & 112 & 40.0 \\
\hline Single & 168 & 60.0 \\
\hline
\end{tabular}

Prevalence of depression, anxiety and stress among study participants

Table 3 reports the prevalence of depression, anxiety, and stress and their associated severity among study participants. Depression, anxiety, and stress were divided according to severity into five groups which are normal, mild, moderate, severe, and very severe. The overall prevalence of depression, anxiety, and stress among international students was $58.9 \%, 71.8 \%$, and $53.9 \%$ respectively.

Table 3 Prevalence of depression, anxiety, and stress among study participants

\begin{tabular}{|c|c|c|c|c|c|c|}
\hline Variables & \multicolumn{2}{|c|}{ Depression } & \multicolumn{2}{|l|}{ Anxiety } & \multicolumn{2}{|l|}{ Stress } \\
\hline Levels: & & $\%$ \\
\hline Normal & 115 & 41.1 & 79 & 28.2 & 129 & 46.1 \\
\hline Mild & 34 & 12.1 & 25 & 8.9 & 44 & 15.7 \\
\hline Moderate & 73 & 26.1 & 58 & 20.7 & 48 & 17.1 \\
\hline Severe & 34 & 12.1 & 45 & 16.1 & 52 & 18.6 \\
\hline Very severe & 24 & 8.6 & 73 & 26.1 & 7 & 2.5 \\
\hline $\begin{array}{l}\text { Score: } \\
\text { Mean } \pm \text { SD } \\
\text { Median } \\
\text { Min - Max. }\end{array}$ & \multicolumn{2}{|c|}{$13.1 \pm 9.2$} & \multicolumn{2}{|c|}{$13.8 \pm 9.2$} & \multicolumn{2}{|c|}{$16.6 \pm 9.0$} \\
\hline
\end{tabular}


Factors associated with depression, anxiety, and stress among study participants

As shown in Table 4, Age showed a significant association with depression and anxiety scores with higher depression and anxiety scores with the age group of 21-24. while stress scores were not significantly different by age group.

Depression and stress scores show a significant association with ethnicity with higher depression and stress scores in the minority ethnic groups, followed by Arabs, Asians, and lastly Africans.
While gender, study program, monthly income, and marital status were not significantly associated with depression, anxiety, and stress. Multiple linear regression was performed. The results are presented in Table 5 . Significant relationships were shown between depression with age group from 21 to 24 years and Arabs and minority ethnic groups. While significant relationships were shown between anxiety with age group from 21 to 24 years only. However, stress scores showed a significant relationship was with Arabs and Asians ethnic groups only.

Table 4 Association between depression, anxiety and stress and characteristics of study participants

\begin{tabular}{|c|c|c|c|c|c|c|c|c|c|}
\hline \multirow{2}{*}{ Variables } & \multicolumn{3}{|c|}{ Depression score } & \multicolumn{3}{|c|}{ Anxiety score } & \multicolumn{3}{|c|}{ Stress score } \\
\hline & $\begin{array}{l}\text { Mean } \pm \\
\text { Standard } \\
\text { deviatio } \\
\mathrm{n} \text { (SD) }\end{array}$ & & $\begin{array}{l}\text { P- } \\
\text { valu } \\
\text { e }\end{array}$ & $\begin{array}{l}\text { Mean } \pm \\
\text { Standard } \\
\text { deviatio } \\
\mathrm{n}(\mathrm{SD})\end{array}$ & & $\begin{array}{l}\text { P- } \\
\text { valu } \\
\text { e }\end{array}$ & $\begin{array}{l}\text { Mean } \pm \\
\text { Standard } \\
\text { deviatio } \\
\mathrm{n}(\mathrm{SD})\end{array}$ & & $\begin{array}{l}\text { P- } \\
\text { valu } \\
\text { e }\end{array}$ \\
\hline Age group & & & & & & & & & \\
\hline $18-20$ & $\begin{array}{l}11.3 \pm \\
6.8\end{array}$ & $\begin{array}{l}\text { one- } \\
\text { way }\end{array}$ & 0.04 & $12.3 \pm 6.8$ & $\begin{array}{l}\text { one- } \\
\text { way }\end{array}$ & 0.01 & $16.2 \pm 7.9$ & $\begin{array}{l}\text { one- } \\
\text { way }\end{array}$ & 0.30 \\
\hline $21-24$ & $\begin{array}{l}15.6 \pm \\
8.5\end{array}$ & $\begin{array}{l}\text { ANOV } \\
\text { A }\end{array}$ & & $16.8 \pm 6.7$ & $\begin{array}{l}\text { ANOV } \\
\text { A }\end{array}$ & & $18.2 \pm 8$ & $\begin{array}{l}\text { ANOV } \\
\text { A }\end{array}$ & \\
\hline $25-35$ & $\begin{array}{l}12.5 \pm \\
9.5\end{array}$ & 3.196 & & $13 \pm 9.5$ & 4.305 & & $16.2 \pm 9.4$ & 1.201 & \\
\hline Gender & & & & & & & & & \\
\hline $\begin{array}{l}\text { Male } \\
\text { Female }\end{array}$ & $\begin{array}{l}13 \pm 9.3 \\
13.2 \pm \\
8.7\end{array}$ & $\begin{array}{l}\text { t-test } \\
-0.103\end{array}$ & 0.92 & $\begin{array}{l}13.9 \pm 9.4 \\
13.5 \pm 8.6\end{array}$ & $\begin{array}{l}\mathrm{t} \text {-test } \\
0.312\end{array}$ & 0.76 & $\begin{array}{l}16.3 \pm 9 \\
17.7 \pm 8.6\end{array}$ & $\begin{array}{l}\text { t-test } \\
-1.063\end{array}$ & 0.29 \\
\hline Ethnicity & & & & & & & & & \\
\hline Arabs & $14.1 \pm 9.5$ & $\begin{array}{l}\text { one- } \\
\text { way }\end{array}$ & 0.01 & $\begin{array}{l}14.4 \pm \\
9.6\end{array}$ & $\begin{array}{l}\text { one- } \\
\text { way }\end{array}$ & 0.23 & $17.3 \pm 9.5$ & $\begin{array}{l}\text { one- } \\
\text { way }\end{array}$ & 0.03 \\
\hline Asians & $12.1 \pm 8.1$ & $\begin{array}{l}\text { ANOV } \\
\text { A }\end{array}$ & & $\begin{array}{l}13.5 \pm \\
7.9\end{array}$ & $\begin{array}{l}\text { ANOV } \\
\text { A }\end{array}$ & & $16.6 \pm 7.4$ & $\begin{array}{l}\text { ANOV } \\
\text { A }\end{array}$ & \\
\hline $\begin{array}{l}\text { Africans } \\
\text { Others }\end{array}$ & $\begin{array}{l}7.3 \pm 7.8 \\
14.9 \pm 10 \\
6\end{array}$ & 3.870 & & $\begin{array}{l}10 \pm 8.7 \\
12.7 \pm 13 \\
6\end{array}$ & 1.442 & & $\begin{array}{l}10.9 \pm 9.1 \\
18 \pm 11\end{array}$ & 3.094 & \\
\hline Education level & & & & & & & & & \\
\hline Undergraduate & $12.7 \pm 8$ & $\begin{array}{l}\text { t-test } \\
-0.273\end{array}$ & 0.79 & $\begin{array}{l}13.6 \pm \\
8.3\end{array}$ & $\begin{array}{l}t \text {-test } \\
0.141\end{array}$ & 0.89 & $16.2 \pm 7.4$ & $\begin{array}{l}\text { t-test } \\
-0.370\end{array}$ & 0.71 \\
\hline Postgraduate & $\begin{array}{l}13.1 \pm \\
9.4\end{array}$ & & & $\begin{array}{l}13.8 \pm \\
9.4\end{array}$ & & & $16.7 \pm 9.3$ & & \\
\hline Study program & & & & & & & & & \\
\hline Non-medical & $\begin{array}{l}12.9 \pm \\
9.2\end{array}$ & $\begin{array}{l}\text { t-test } \\
-0.521\end{array}$ & 0.60 & $\begin{array}{l}13.8 \pm \\
9.4\end{array}$ & $\begin{array}{l}\text { t-test } \\
0.069\end{array}$ & 0.95 & $16.5 \pm 9$ & $\begin{array}{l}\text { t-test } \\
-0.379\end{array}$ & 0.71 \\
\hline $\begin{array}{l}\text { Medical/Paramedic } \\
\text { al } \\
\text { Monthly income }\end{array}$ & $\begin{array}{l}13.7 \pm \\
8.9\end{array}$ & & & $\begin{array}{l}13.7 \pm \\
8.3\end{array}$ & & & $17.1 \pm 9.5$ & & \\
\hline$<2000 M Y R$ & $\begin{array}{l}12.8 \pm \\
8.9\end{array}$ & $\begin{array}{l}\text { one- } \\
\text { way }\end{array}$ & 0.92 & $\begin{array}{l}13.6 \pm \\
8.7\end{array}$ & $\begin{array}{l}\text { one- } \\
\text { way }\end{array}$ & 0.79 & $16.8 \pm 8.9$ & $\begin{array}{l}\text { one- } \\
\text { way }\end{array}$ & 0.82 \\
\hline 2000-5000MYR & $\begin{array}{l}13.3 \pm \\
9.5\end{array}$ & $\begin{array}{l}\text { ANOV } \\
\text { A }\end{array}$ & & $\begin{array}{l}13.7 \pm 10 \\
1\end{array}$ & $\begin{array}{l}\text { ANOV } \\
\text { A }\end{array}$ & & $16.3 \pm 9.4$ & $\begin{array}{l}\text { ANOV } \\
\text { A }\end{array}$ & \\
\hline >5000MYR & $13 \pm 9.3$ & 0.079 & & $\begin{array}{l}14.7 \pm \\
8.4\end{array}$ & 0.240 & & $17.4 \pm 8.3$ & 0.193 & \\
\hline Marital status & & & & & & & & & \\
\hline Married & $\begin{array}{l}12.3 \pm \\
9.8\end{array}$ & $\begin{array}{l}\text { t-test } \\
-1.113\end{array}$ & 0.27 & $\begin{array}{l}13.6 \pm \\
9.7\end{array}$ & $\begin{array}{l}\text { t-test } \\
-0.206\end{array}$ & 0.84 & $16.8 \pm 9.5$ & $\begin{array}{l}\mathrm{t} \text {-test } \\
0.173\end{array}$ & 0.86 \\
\hline Single & $\begin{array}{l}13.5 \pm \\
8.8\end{array}$ & & & $\begin{array}{l}13.9 \pm \\
8.9\end{array}$ & & & $\begin{array}{l}16.6 \pm \\
8.7 \\
\end{array}$ & & \\
\hline
\end{tabular}


Table 5 Multiple Regression model for depression, anxiety, and stress with characteristics of study participants

\begin{tabular}{|c|c|c|c|c|c|c|}
\hline & $\begin{array}{l}\text { Depression } \\
r^{2}=\mathbf{0 . 0 6 5}\end{array}$ & & $\begin{array}{c}\text { Anxiety } \\
r^{2}=\mathbf{0 . 0 5 2}\end{array}$ & & $\begin{array}{c}\text { Stress } \\
r^{2}=0.049 \\
\end{array}$ & \\
\hline Variables & $\begin{array}{l}\text { Regression } \\
\text { coefficient } \\
\text { (b) }\end{array}$ & $\begin{array}{c}\mathrm{p}- \\
\text { value }\end{array}$ & $\begin{array}{l}\text { Regression } \\
\text { coefficient } \\
\text { (b) }\end{array}$ & $\begin{array}{c}\mathrm{p}- \\
\text { value }\end{array}$ & $\begin{array}{l}\text { Regression } \\
\text { coefficient } \\
\text { (b) }\end{array}$ & $\begin{array}{c}\mathrm{p}- \\
\text { value }\end{array}$ \\
\hline $\begin{array}{l}\text { Age Group: } \\
18-20 \\
21-24 \\
25-35\end{array}$ & $\begin{array}{l}-.023 \\
.139 \\
\text { Ref. }\end{array}$ & $\begin{array}{l}.82 \\
.05\end{array}$ & $\begin{array}{l}.749 \\
4.625 \\
\text { Ref. }\end{array}$ & $\begin{array}{l}.81 \\
.00\end{array}$ & $\begin{array}{l}1.992 \\
2.656 \\
\text { Ref. }\end{array}$ & $\begin{array}{l}.52 \\
.09\end{array}$ \\
\hline $\begin{array}{l}\text { Gender: } \\
\text { Male } \\
\text { Female }\end{array}$ & .274 & .84 & .789 & .55 & -.914 & .48 \\
\hline $\begin{array}{l}\text { Nationality: } \\
\text { Arabs } \\
\text { Asians } \\
\text { Africans } \\
\text { Others }\end{array}$ & $\begin{array}{c}6.471 \\
4.186 \\
\text { Ref. } \\
7.293\end{array}$ & $\begin{array}{l}.00 \\
.08 \\
.05\end{array}$ & $\begin{array}{c}4.282 \\
3.143 \\
\text { Ref. } \\
2.653\end{array}$ & $\begin{array}{l}.05 \\
.19 \\
.48\end{array}$ & $\begin{array}{c}6.279 \\
5.381 \\
\text { Ref. } \\
7.064\end{array}$ & $\begin{array}{l}.00 \\
.02 \\
.05\end{array}$ \\
\hline $\begin{array}{l}\text { Educational level: } \\
\text { Undergraduate } \\
\text { Postgraduate }\end{array}$ & .310 & .90 & .456 & .85 & 1.861 & .43 \\
\hline $\begin{array}{l}\text { Study Program: } \\
\text { Non-medical } \\
\text { Medical/paramedical }\end{array}$ & .681 & .67 & -.605 & .71 & .037 & .98 \\
\hline $\begin{array}{l}\text { Monthly Income: } \\
\text { <2000 RM } \\
2000-5000 \text { RM } \\
>5000 \text { RM }\end{array}$ & $\begin{array}{l}-.029 \\
.204 \\
\text { Ref. }\end{array}$ & $\begin{array}{l}.99 \\
.92\end{array}$ & $\begin{array}{l}-1.559 \\
-1.435 \\
\text { Ref. }\end{array}$ & $\begin{array}{l}.46 \\
.49\end{array}$ & $\begin{array}{l}-.351 \\
-1.052 \\
\text { Ref. }\end{array}$ & $\begin{array}{l}.86 \\
.60\end{array}$ \\
\hline $\begin{array}{l}\text { Marital Status: } \\
\text { Married } \\
\text { Single }\end{array}$ & -.637 & .62 & 1.003 & .44 & 1.145 & .37 \\
\hline
\end{tabular}

Help-seeking behavior and awareness of oncampus services among study participants Only $9.6 \%$ of students had sought help for their psychological distress from the available university services. As shown in Table 6, depression, anxiety, and stress scores were significantly associated with help-seeking behavior. Students who had higher depression, anxiety, and stress scores were more likely to seek professional help. While students' awareness of the presence of on-campus mental support services was only $21.4 \%$.

Table 6 Association between depression, anxiety, and stress and help-seeking behavior

\begin{tabular}{|c|c|c|c|c|}
\hline & \multicolumn{2}{|c|}{$\begin{array}{l}\text { Help-seeking behavior: } \\
\text { (Mean } \pm \text { standard deviation) }\end{array}$} & \multirow[t]{2}{*}{ Test of significance } & \multirow{2}{*}{$\begin{array}{l}P \text {-value } \\
(P<0.05)\end{array}$} \\
\hline & Yes & No & & \\
\hline Depression score & $19.11 \pm 7.4$ & $12.40 \pm 9.1$ & & 0.000 \\
\hline Anxiety score & $20.3 \pm 8.97$ & $13.1 \pm 8.98$ & t-test & 0.000 \\
\hline Stress score & $22.15 \pm 9.36$ & $16.04 \pm 8.80$ & & 0.001 \\
\hline
\end{tabular}




\section{DISCUSSION}

The present study assessed the psychological distress among international university students who are studying in UKM by determining the prevalence of depression, anxiety, and stress and examining their associated risk factors among this population. Besides, it evaluated their help-seeking behavior and awareness about the presence of on-campus mental support services.

The results of the present study showed a high prevalence and severity of depression, anxiety, and stress among international students with more than half of this population were suffering from mild to very severe levels of psychological distress. Anxiety appeared to be the most prevalent, with more than two-thirds of the

students had some sort of anxiety distress. The prevalence of moderate to very severe depression, anxiety and stress were found to be $46.8 \%, 62.9 \%$, and $38.2 \%$ respectively. This prevalence is higher compared to the prevalence of depression, anxiety, and stress of moderate severity and above among Turkish and Malaysian university students which were $27.1 \%, 47.1 \%$, and $27 \%$ and $37.2 \%, 63 \%$, and $23.7 \%$ respectively ${ }^{7,17}$. The overall prevalence of stress in this study was consistent with that of an earlier study among international students that was $54 \%{ }^{18}$. A higher prevalence of psychological distress among international students maybe because they have to adapt to the new environment and different education systems, they face linguistic barriers and change in their support system.

Moreover, social stressors such as cultural differences, relationships with peers and hostel mates may affect their mental well-being. These findings are following the study hypothesis that there are a high prevalence and severity of depression, anxiety, and stress among international university students in Malaysia. Although DASS-21 is a screening and not a diagnostic tool, this high prevalence of depression, anxiety, and stress may need consideration form university administrative staff and health-care professionals.

In this study, Age was found to have significant associations with depression ( $p$-value is 0.042 ) and anxiety ( $p$-value is 0.014 ) scores. This is consistent with other studies that reported that Age was significantly associated with depression and anxiety scores ${ }^{7}, 19$. Higher depression and anxiety scores were detected in the age group of 21-24 years, followed by 25-35 years, and lastly younger students between 18 to 20 years. This is consistent with a previous study that showed that Age more than 20 years has a strong association with depression, anxiety, and stress $^{18}$. This may be because older students may be keener on finishing their studies to be able to work and be financially independent.

This study revealed that there were no significant associations between gender and depression, anxiety, or stress, with both male and female students had almost similar levels of psychological distress. This is in accordance with a previous study that showed that gender had no significant association with depression, anxiety, and stress among university students ${ }^{20}$. On the other hand, other studies found that Females had higher levels of psychological distress than males ${ }^{17,21}$. It was demonstrated that females were twice as likely as males to have an anxiety disorder and that the risk factors for mental problems among women reported being related to hormonal and biochemical differences between both genders ${ }^{2}$.

Ethnicity in the present study was significantly associated with depression and stress, with higher depression and stress levels in the minority ethnic groups followed by the Arabs ethnic group, respectively. Higher depression and stress levels in the minority group could be attributed to the lack of expatriate communities from the same country or culture as the student himself. The detachment from their cultures with the lack of alternative community and support system deepens the feeling of loneliness and isolation from their surroundings. It was reported that minority ethnic groups might predispose to such psychological problems as minority students experience feeling of loneliness and discrimination ${ }^{22}$. While the high prevalence of depression and stress among the Arabs ethnic group may be related to the deteriorated states that their countries are having currently. The effects of such deterioration extend to affect those students' careers and personal lives.

There was no significant association between marital status and psychological distress in the present study. This may be because married 
people being overwhelmed by family responsibilities, while at the same time single people being lonely most of the time and not having a partner to share their concerns and struggles with. However, it was reported in an earlier study that depression, anxiety, and stress were more likely to be higher among single students, and that married students were less prone to psychological distress ${ }^{19,20}$.

Although it was reported earlier that there was a significant association between socioeconomic level with stress and depression, as higher stress and depression scores were recorded with low socioeconomic class ${ }^{19,20}$, the present study demonstrated no significant association of depression, anxiety, and stress with the monthly income of international students. This may be because this study was done on international students who are more inclined to manage their finances properly to avoid any unfavorable situations. Also, student prices are provided in many places in Malaysia like university canteens, public parks, touristic attractions, and public transportations.

The study program was not associated with depression, anxiety, and stress among international students in the current study. This might be since all international students are affected by the same circumstances regardless of the course of their studies. This is supported by an earlier study found that there were no significant associations between study program and depression, anxiety and stress scores ${ }^{7}$. However, other research findings reported that medical students showed higher prevalence and severity of stress and depression compared to their non-medical peers ${ }^{20}$. On the other hand, it was reported that the depression and anxiety levels were higher among students who were studying social and political sciences compared to those who were studying engineering, medical, or basic sciences ${ }^{17}$.

Although university students often demonstrate low levels of mental well-being, they show poor help-seeking behaviors for their mental health problems ${ }^{9}$. In this study, help-seeking behavior was found to be positively associated with depression, anxiety, and stress scores as students with higher psychological distress reported higher help-seeking behavior from support services available at the university. While Goodwin et al. (2016) showed that students with higher mental health levels were more likely to seek help from informal sources such as friends and partners. While students with lower mental health levels were unlikely to seek help from both formal and informal sources. Moreover, the current found that only one in ten of the international students had sought psychological help from support services available at the university. Professional helpseeking behavior among students from oncampus and off-campus services was demonstrated to range from $15 \%$ to one-third of students $8,23,24$. However, it was reported that only $3.77 \%$ of students sought help from the university support services ${ }^{9}$. Even though university counseling services are free, most students would seek help from external sources ${ }^{25}$.

The present study found that $78.6 \%$ of international students were unaware of the presence of on-campus mental support services. This is consistent with previous research that found that international students underutilize mental health services, with $50 \%$ of international students are not aware of the presence of such services ${ }^{26}$. Higher awareness rates of the on-campus mental support services than help-seeking behavior among students may be attributed to lack of awareness of the symptoms of their mental problems or the available mental support services. Also, mental health illness may be stigmatized in some cultures, so it is important to normalize international students' views on mental health issues.

The limitations of the current study include that the design of the study was cross-sectional, which cannot determine the incidence rate of psychological distress; however, it can only determine its prevalence. Also, a nonprobability sampling method was used, and the samples were taken without regard to the correct distribution characteristics of the international students at the university due to lack of epidemiological data for this population, this may introduce sampling bias and affect the generalizability of the study findings. Moreover, it is important to mention that the DASS-21 questionnaire can be used to assess the prevalence and severity of psychological distress and not to diagnose psychological disorders. 


\section{CONCLUSION}

In conclusion, this study revealed a high prevalence and severity of psychological distress among international students that were associated with Age and ethnicity. Also, very low levels of mental help-seeking behavior and awareness of the available on-campus mental support services were reported. These findings highlight the importance of screening and taking proper interventions to improve the mental well-being of this vulnerable population. It is recommended that the university should organize awareness campaigns to educate all students and staff about psychological distress, how to deal with it, and with colleagues/students who suffer from any sort of psychological problems, and to encourage them to seek help from the available on-campus mental support services. University administrative staff should hold a biannual compulsory screening for all international students to determine their mental health state. Depending on every student's results, the university should take a proper action.

\section{Conflict of interest}

The investigators declare that there is no conflict of interest.

\section{Acknowledgement}

Thanks to all international students who participated in the study.

\section{REFERENCES}

1. Lei X, Xiao L, Liu Y, et al. Prevalence of Depression among Chinese University Students: A MetaAnalysis. PLOS ONE 2016; 11(4).

2. Macauley K, Plummer L, Bemis C, et al. Prevalence and Predictors of Anxiety in Healthcare Professions Students. Health Prof Educ 2018; 4(3): 176-185.

3. Ribeiro ÍJ, Pereira R, Freire IV, et al. Stress and Quality of Life Among University Students: A Systematic Literature Review. Health Prof Educ 2018; 4(2): 70-77.

4. Drapeau A, Marchand A, BeaulieuPrevost D. Epidemiology of Psychological Distress. Mental
Illnesses - Understanding, Prediction and Control, 2012.

5. Ridner S. Psychological distress: concept analysis. J Adv Nurs 2004; 45(5): 536-545.

6. Arvidsdotter $\mathrm{T}$, Marklund $\mathrm{B}$, Kylén $\mathrm{S}$, et al. Understanding persons with psychological distress in primary health care. Scand J Caring Sci 2015; 30(4): 687-694.

7. Shamsuddin K, Fadzil F, Ismail WS, et al. Correlates of depression, anxiety and stress among Malaysian university students. Asian J Psychiatr 2013; 6(4): 318-323.

8. Gold JA, Johnson B, Leydon G, et al. Mental Health Self-Care in Medical Students: a Comprehensive Look at Help-Seeking. Academic Psychiatry 2015; 39(1): 37-46.

9. Goodwin J, Behan L, Kelly P, et al. Help-seeking behaviors and mental well-being of first year undergraduate university students. Psychiatry Res 2016; 246: 129-135.

10. Sorakhani D, Delpisheh A, Veisani Y, et al. Prevalence of Depression among University Students: A Systematic Review and MetaAnalysis Study. Depress Res Treat 2013; 1-7.

11. Seyfi F, Poudel KC, Yasuoka J, et al. Intention to seek professional psychological help among college students in Turkey: influence of help-seeking attitudes. BMC Research Notes 2013; 6(1): 519.

12. Bradley L, Parr G, Lan WY, et al. Counselling expectations of international students. Int $J A d v$ Couns 1995; 18: 21-31.

13. Mori SC. Addressing the Mental Health Concerns of International Students. J Couns Dev 2000; 78(2): 137-144. 
14. The International mobility of students in Asia and the Pacific, 2013. Retrieved from https: / / unesdoc.unesco.org/ark:/4 $8223 / \mathrm{pf0000226219}$

15. Lovibond SH, Lovibond PF. Manual for the Depression Anxiety Stress Scales. 2nd ed. Sydney: Psychology Foundation, 1995.

16. Henry JD, \& Crawford JR. The shortform version of the Depression Anxiety Stress Scales (DASS-21): Construct validity and normative data in a large non-clinical sample. Br J Clin Psychol 2005; 44: 227-39.

17. Bayram N, Bilgel N. The prevalence and sociodemographic correlations of depression, anxiety and stress among a group of university students. Soc Psychiatry Psychiatr Epidemiol 2008; 43(8): 667-72.

18. Ismail A, Ashur ST, Jamil AT, et al. Stress Level and the common coping strategies among international postgraduate students at Universiti Kebangsaan Malaysia Medical Centre (Ukmmc), Cheras, Kuala Lumpur, Malaysia. ASIAN J PSYCHIATR 2016; 17(1).

19. Wahed YA, Hassan SK. Prevalence and associated factors of stress, anxiety and depression among medical Fayoum University students. Alexandria Journal of Medicine 2017; 53(1): 77-84.

20. Teh CK, Ngo CW, Zulkifli RA, et al. Depression, Anxiety and Stress among Undergraduate Students: A Cross Sectional Study. Open J Epidemiol 2015; 5(4): 260-268.

21. Dyrbye LN, Thomas MR, Shanafelt TD. Systematic Review of Depression, Anxiety, and Other Indicators of Psychological Distress Among U.S. and Canadian Medical Students. Acad Med 2006; 81(4): 354-73.
22. Dyrbye LN, Thomas MR, Eacker A, et al. Race, Ethnicity, and Medical Student Well-being in the United States. Arch Intern Med 2007; 167(19): 21-03.

23. Bilican FI. Help-Seeking Attitudes and Behaviors Regarding Mental Health Among Turkish College Students. Int J Ment Health 2013; 42(2-3): 43-59.

24. Lally J, Ó Conghaile A, Quigley S, et al. Stigma of mental illness and help-seeking intention in university students. The Psychiatrist 2013; 37(8): 253-60.

25. Reavley NJ, Cvetkovski S, Jorm AF, et al. Help-Seeking for Substance Use, Anxiety and Affective Disorders Among Young People: Results from the 2007 Australian National Survey of Mental Health and Wellbeing. Aust N Z J Psychiatry 2010; 44(8): 729-735.

26. Lau J, Garza T, Garcia $H$. International Students in Community Colleges: On-Campus Services Used and Its Affect on Sense of Belonging. Community College Journal of Research and Practice 2018; 43(2); 1-13. 